\title{
International Journal of Pediatric Endocrinology reviewer acknowledgement 2015
}

Surendra Varma

\section{Contributing reviewers}

The editor of International Journal of Pediatric Endocrinology would like to thank all of the reviewers who have contributed to the journal in 2015.

\section{Alan Rogol}

United States of America

Alexander Jorge

Brazil

Alicia Romano

United States of America

Amanda Ackermann

United States of America

Ambika Ashraf

United States of America

Andrew Dauber

United States of America

Andrew Lane

United States of America

Archana Arya

United States of America

Arlan Rosenbloom

United States of America

Brenda Kohn

United States of America

Craig Alter

United States of America

Craig Jefferies

New Zealand

\section{Daina Dreimane}

United States of America

Daniel DeSalvo

United States of America

Dennis Styne

United States of America

Dorothy Shulman

United States of America

Edward Reiter

United States of America

Flavia Prodam

Italy

Grace Tannin

United States of America

Jan Idkowiak

United Kingdom

Jan-Maarten Wit

Netherlands

Jennifer Osipoff

United States of America

John Fuqua

United States of America

Jonathan Wasserman

Canada
Joshua Miller

United States of America

Kathleen Bethin

United States of America

Kimberly Tafuri

United States of America

Lefkothea Karaviti

United States of America

Liuska Pesce

United States of America

Maria Vogiatzi

United States of America

Mario Rotondi

Italy

Maya Lodish

United States of America

Mehul Dattani

United Kingdom

Meilan Rutter

United States of America

Munier Nour

Canada

Nicholas Jospe

United States of America

Correspondence: ijpeonline@biomedcentral.com

Texas Tech University 3601 4th St, Lubbock, TX 79430, USA 
Olga Gupta

United States of America

Patricia Vuguin

United States of America

Paul Kaplowitz

United States of America

Paulo Collett-Solberg

Brazil

Philip Zeitler

United States of America

Robert Rosenfield

United States of America
Rubina Heptulla

United States of America

Sara DiVall

United States of America

Sara Watson

United States of America

Scott Rivkees

United States of America

Sungdae Moon

South Korea

Surendra Varma

United States of America

\section{Susan Schuval}

United States of America

Susanne Cabrera

United States of America

Theo Sas

Netherlands

Tracy Bekx

United States of America

Walter Bonfig

Germany

Zeynep Siklar

Turkey 